\title{
United States officials propose further retreat from first-come, first-served organ donation
}

$\mathrm{T}$ he United States' United Network for Organ Sharing (UNOS) has long prided itself as being entirely egalitarian, distributing organs on a first-come, first-served basis without regard to wealth, class, race or other consideration.

But another chink may be about to appear in that philosophical armour as the agency, which operates the Organ Procurement and Transplantation Network, says it is considering a revision in its policies for allocating kidneys, including the allocation of younger kidneys, to younger recipients. The policy changes would basically extend a rule implemented in 2004 that prioritized allocation of organs to pediatric recipients.

The changes would also result in the creation of a kidney profile index that would rank the quality of all donated kidneys according to the period of time they might be expected to last after they are transplanted. That would largely be based on the health of the donor.

In turn, potential kidney recipients would be assigned a number indicating their projected life expectancy after the transplant, with the presumption being that younger recipients will live longer.

The index would then be used to match the top $20 \%$ of kidneys to the $20 \%$ of candidates with the longest post-transplant life expectancy. All remaining kidneys would be allocated to recipients on the basis of age criteria. Kidneys would be matched to recipients whose age fell within 15 years of the donor's age.

When the network was established in 1986, allocations were made strictly on a first-come, first-served basis, and tissue typing.

Although tissue typing remains an issue, medications that reduce the likelihood of rejection have resulted in a system that now primarily uses a patient's length of time on the waiting list as the main criteria for determining whether he will receive a kidney.

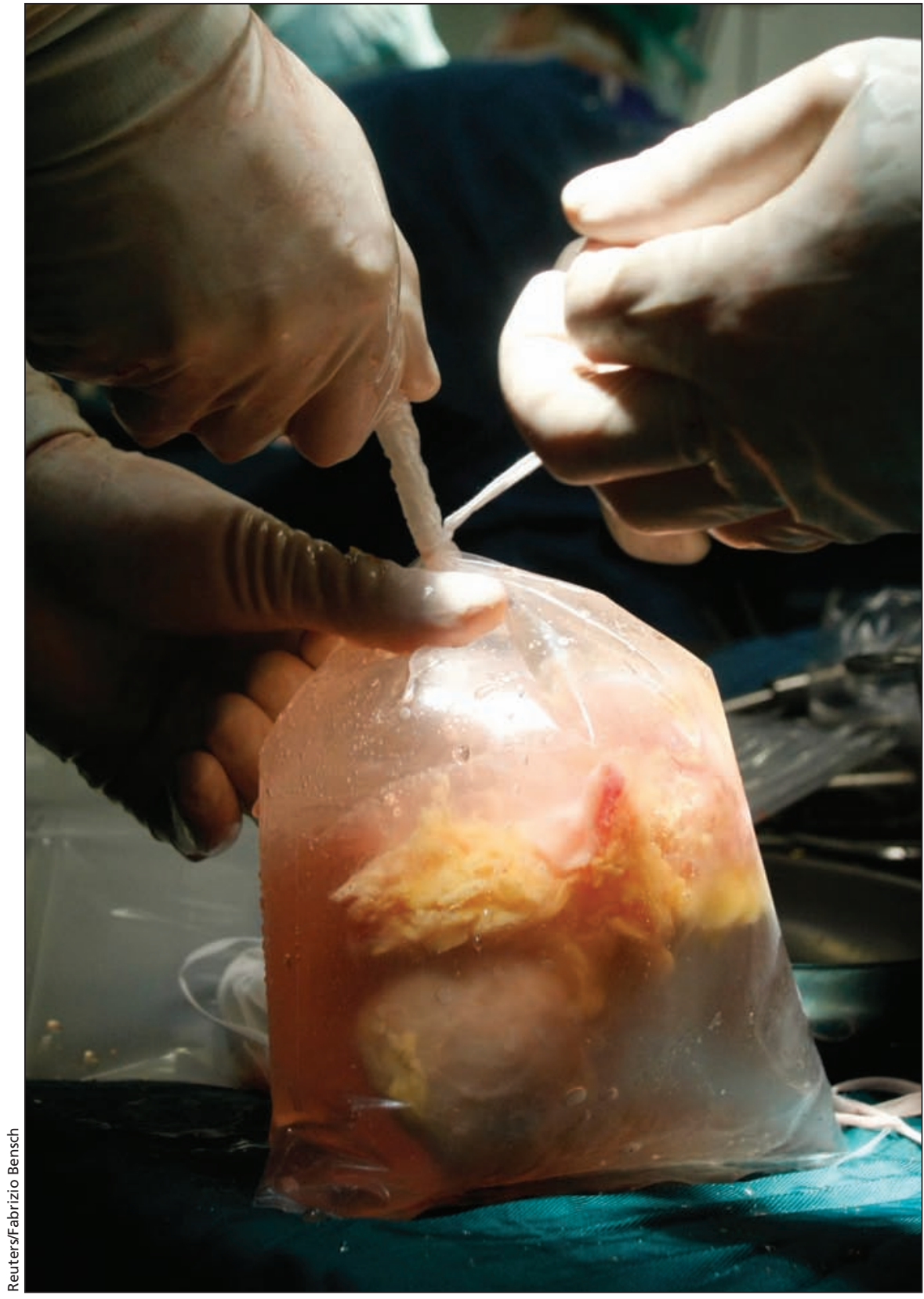

Surgeons hold a plastic bag containing a kidney after an operation to extract the organ from a brain-dead woman.

While the waiting list approach doesn't discriminate between potential recipients, it does not effectively maximize the success rate of transplants or minimize the number of patients who die waiting, says Kenneth Andreoni, chair of the UNOS Kidney Transplantation Committee and associate professor of surgery at the Ohio State University College of Medicine in Columbus, Ohio.

Critics fear the proposed changes will unfairly favour younger recipients, or 
may reduce the rates of living donations, as suggested by a recent opinion piece coauthored by a member of the UNOS ethics committee ( $N$ Engl J Med. 2011;364:1285-87). It argued that the 2005 policy change to prioritize allocations to pediatric recipients led to fewer living organ donations and surmised that the proposed policy changes will have a similar effect, by pushing younger, healthier candidates to the top of the wait list, putting older candidates at a disadvantage.

But Andreoni counters that the assumption that the system would disadvantage adults isn't valid. Candidates who enter the waiting list for better quality kidneys would be ranked on a points-based system, which takes into account age and time spent on the wait list among other factors, he says. For those individuals, receiving a kidney from a living donor would still be faster and have a higher success rate.

Andreoni adds that the average age of donors has risen in recent years, as kidneys from older donors are now considered acceptable. "Twenty five years ago when I started, a donor was considered old if they were over 45 . That's not the case these days."

Those older kidneys can be matched to recipients of the same age group, he says. "It's an obvious, easy way to increase transplantation: Getting kidneys that are usable to people who can better use them."

Donor kidneys are now classified as either "expanded criteria donor" or "standard criteria donor." The former account for about $15 \%$ of the donor pool and are typically donated by those who are either older or have a medical condition that may lower the organ's life expectancy.

The proposed new index would indicate the quality of the kidney, based on the donor's health, height, weight, age, race, ethnicity, disease state (such as hypertension or diabetes), and cause of death if deceased.

Andreoni says the donor profile index would give a "more granular" assessment of each kidney, and would better match organs with recipients, according to probability of transplant success.

"The average person will get the same quality kidney," as 14 years is currently the typical age difference between donors and recipients, he says.

The proposed changes would undermine the existing system's principle of providing all candidates with an equal chance of receiving a kidney by introducing a new life-expectancy standard, says Arthur Caplan, a professor of bioethics at the University of Pennsylvania. "We can ask which standard is better, or ask potential donors: What do you intend? To give everyone an equal chance or save the most lives and life years with your gifts? The answer to that debate is an empirical question, asking what do people want when they say: 'I want to be an organ donor'."

There are several ethical dimensions to the debate, Caplan says.

Affordability isn't an issue, as the government pays for transplants, he explains. "That takes ability to pay off the table."

But what remains is the question of deciding how to allocate a "scarce and expensive resource," adds Caplan, who supports the proposed changes, with reservations. People with inadequate life insurance, for example, would still delay doctor visits, reducing their chances of early diagnosis.

While the US has one of the world's highest rates of organ donation, more than 100000 names are on the waiting list for organs (88 000 for kidneys) and an estimated 18 patients die daily while on the list.

The National Kidney Foundation said in a statement that it supports the proposed changes but has some concerns (www.kidney.org/news/newsroom /AllocationConceptPaper.cfm). A hospital can now send a kidney to any of nearly 250 US transplant centres for evaluation and each has its own criteria for accepting kidneys. Those that are rejected by one hospital can be sent to another, explains Dolph Chianchiano, the foundation's senior vice president of public policy.

"There's a time lag that is engendered. ... [in this] serial offer-acceptance procedure," Chianchiano says, adding that the approval process needs to be streamlined. Some transplant centers "routinely turn down organs they would theoretically accept."

Some centres only accept the highest quality kidneys because they are seeking the "best possible outcome profile," Chianchiano says. Better quality kidneys lead to a higher rate of successful transplants, making the transplant centres look good to private insurance companies.

The kidney foundation statement asserts that the time lag is one factor responsible for the number of viable kidneys -250 on average - that are discarded annually. Other factors include inconclusive biopsies regarding the health of the kidney.

But varying acceptance rates at transplant centres are to be expected, says Dorrie Dils, chief clinical executive at Lifeline of Ohio, a nonprofit organization that manages organ donation in Ohio. "I personally can understand why there are varying acceptance policies or things that might concern one surgeon for one patient that may not concern them for the next patient," she says. "No two recipients are the same."

Dils adds that most transplant centres do, in fact, want to maintain a certain performance level, making allocation more difficult. "[Surgeons] certainly don't want to take a gift from a donor and put it into someone that's not going to be successful."

The proposed changes are now up for public consultation and are expected to be reviewed by UNOS's board of directors in 2012. But "even if everything was adored by all, it would still be a while" before the proposal is finalized, Andreoni says. - Samia Madwar, Ottawa, Ont.

CMAJ 2011. DOI:10.1503/cmaj.109-3887 